\title{
A RETOMADA DOS LAÇOS DIPLOMÁTICOS ENTRE CUBA E EUA: ENTRE O FIM DA GUERRA FRIA E A NORMALIZAÇÃO DAS RELAÇÕES?
}

\section{The resumption of diplomatic ties between Cuba and the United States: between the end of the Cold War and the normalization of relations?}

Marcos Antonio da Silva ${ }^{1}$

\section{Introdução ${ }^{2}$}

O anúncio conjunto, por Raúl Castro e Barack Obama, da retomada das relações entre Cuba e EUA, em dezembro de 2014, tem um significado histórico de amplo alcance nas relações regionais, demarcando a possibilidade de superação de um dos últimos (e mais evidentes) vestígios da Guerra Fria e gerando inúmeros debates e expectativas. Tal anúncio significou também a possibilidade de normalização das relações entre países, algo inédito e depois de mais de cinquenta anos de tensões e conflitos, e o início de um processo que, apesar de algumas iniciativas já desenvolvidas, ainda necessita percorrer um longo caminho, superando as demandas de cada parte, para que a normalização se torne efetiva.

As relações entre Cuba e EUA foram, desde a tardia independência da ilha caribenha, intensas e com um padrão de anormalidade que delineou a política externa de cada nação e influenciou, em certos momentos, a dinâmica das relações regionais. Neste sentido, a presença estadunidense no momento de consolidação do processo de independência, consolidada com a famosa Emenda Platt, que promovia a tutela econômica e política dos EUA sobre a ilha estabelecendo as bases para as relações bilaterais (BANDEIRA, 1998; AYERBE, 2004) $)^{3}$ determinou a dinâmica política da jovem república cubana e, principalmente, permitiu que tal presença

\footnotetext{
${ }^{1}$ Doutor em Integração da América Latina (PROLAM/USP). Professor do curso de Ciências Sociais e do Programa de Pós-Graduação em Sociologia da Universidade Federal da Grande Dourados (UFGD). Membro do LIAL/UFGD (Laboratório Interdisciplinar de Estudos sobre América Latina).Email: marocam@terra.com.br

${ }^{2}$ Uma primeira versão deste trabalho foi apresentada no XII Encontro Internacional da Associação Nacional dos Professores e Pesquisadores de História das Américas (ANPHLAC), realizado em Campo Grande (MS), em agosto de 2016. Agradeço aos pareceristas as correções e sugestões.

${ }^{3}$ Como aponta Ayerbe, a emenda estabelecia que: “Que o governo de Cuba permita que os Estados Unidos exerça o direito de intervir no sentido de preservar a independência cubana, manter a formação de um governo adequado para a proteção da vida, a propriedade, a liberdade individual. Que, a fim de auxiliar os Estados Unidos a sustentar a independência cubana, e para proteger a população dali, tão bem como para a sua própria defesa, o governo de Cuba deverá vender ou alugar terras aos Estados Unidos, necessárias para a extração de carvão para as linhas férreas ou bases navais em certos locais especificados de acordo com o Presidente dos Estados Unidos" (Ayerbe, 2004, pg. 24).
} 
atingisse todos os setores da vida cubana, da cultura à economia. Desta forma, os EUA tornaram-se o principal parceiro comercial e político, inclusive com foro de tutoria da ilha, enquanto as questões cubanas emergiam como prioritárias na agenda externa norte-americana, como fornecedora de açúcar, destino de investimentos e interesses geoestratégicos.

Tal dinâmica foi alterada com a vitória revolucionária, em 1959, porém tal relação continuou prioritária, embora fundamentada numa nova lógica de conflito, condicionada pelos marcos da Guerra Fria. Isto porque os interesses mostraram-se inconciliáveis dentro do novo marco político. Desta forma, no caso cubano, a nova liderança e sua proposta de transformação das estruturas sociais, políticas e económicas do país a partir da reforma agraria, nacionalização, autonomia, industrialização, igualdade e ampliação da ação estatal (entre outras) gerava inúmeros conflitos com os interesses norte-americanos (AYERBE, 2004). Por outro lado, a projeção internacional norte-americana dependia de sua relação e hegemonia com as nações latino-americanas, sendo, portanto necessário demonstrar e enquadrar os países da região em prol de tais interesses, consolidados em torno do pan-americanismo (AYERBE, 2002).

Sendo assim, tal relação foi condicionada pelos marcos da Guerra Fria e determinou, em grande medida, a dinâmica das relações interamericanas, inclusive após o fim dos conflitos entre as superpotências, mantendo-se até o presente momento. Desta forma, Cuba passou a atuar em prol de transformações na região enquanto os EUA procuraram isolar o nascente regime cubano e manter o status quo regional. Além disto, tal conflito também incidiu sobre as relações entre as duas superpotências (EUA e URSS) como revelam a atuação e os acordos derivados da Crise de Mísseis do início dos anos 60.

Em suma, forjada nos quadros da Guerra Fria, tal relação foi determinante para o desenvolvimento da política externa de cada país ao longo das últimas cinco décadas: do lado norte-americano, o apoio e a promoção de regimes de segurança nacional que impedissem o advento de novas ondas revolucionárias, no caso cubano o incentivo e o apoio material a governos que demonstrassem um rompimento com tal perspetiva. Desta forma, a relação Cuba e EUA manteve-se como a principal herança da Guerra Fria na América Latina e, quiçá, em todo o planeta. Somente a persistência da lógica da Guerra Fria, como principal variável conforme admitiu o presidente Obama em sua visita a ilha, pode explicar o comportamento norteamericano mesmo após a queda do bloco soviético.

Disto resulta que o anúncio da retomada das relações entre os dois países, em dezembro de 2014, depois de meses de negociação e a consequente abertura de embaixadas emerge como um dos acontecimentos fundamentais das relações interamericanas neste novo século e requer uma análise aprofundada. Neste sentido, este trabalho analisa o processo de restabelecimento das relações diplomáticas entre Cuba e EUA procurando compreender sua dinâmica, as motivações iniciais e, principalmente, as perspectivas para sua continuidade, considerando as demandas e os cenários para a normalização (ou não) de tais relações e os impactos que isto pode provocar no cenário regional a partir dos interesses estratégicos de cada nação e do novo contexto regional.

Para tanto, estará estruturado da seguinte forma. Na primeira parte, após um breve balanço do conflito, analisa a dinâmica e motivações da retomada de relações entre Cuba e EUA. Em seguida, discute a 
recente visita do presidente Barack Obama a Cuba e os condicionantes da normalização de tal relação. Finalmente, analisa o impacto de tal retomada nas relações regionais, considerando as perspectivas do sistema interamericano no novo século.

\section{Cuba e EUA: novo século- velhas ou novas relações?}

A Revolução Cubana foi, acima de tudo, uma revolução nacionalista que se radicalizou no contexto mencionado (Guerra Fria) e nos marcos da relação dos EUA com a América Latina (AYERBE, 2004, COGGIOLA, 1998).

Neste sentido, a referência fundamental do movimento liderado por Fidel Castro estava em José Martí, herói cubano das lutas de independência, o que se mantém até a atualidade. Além disto, não havia contatos ou apoio da URSS durante a luta revolucionária, o que só ocorreu após a vitória guerrilheira. Sendo assim, pode-se afirmar que foi a reação norte-americana às medidas tomadas pelo nascente governo, associadas às limitações do contexto internacional, que determinaram a aliança cubano-soviética, pois como afirma Wayne Smith, o último embaixador norte-americano na ilha:

\footnotetext{
“Até a ruptura das relações, em janeiro de 1961, não havia vínculos sólidos entre Castro e a União Soviética. Por certo, houve a visita do diplomata Anastasio Mikoyan a Cuba em 1960 mas não havia então uma relação social entre Moscou e Havana. Eu diria, inclusive, que a aproximação ocorreu definitivamente na véspera da invasão da Baía de Porcos, em abril de 1961. Castro estava a par de todos os preparativos e tinha certeza de que era só uma questão de tempo. No entanto, não pensava que enviaríamos apenas alguns milhares de exilados. Estava convencido de que várias divisões de soldados da marinha se seguiriam ao primeiro desembarque, o que não foi o caso. (...) Cuba se aproximou da União Soviética, em grande parte, por causa de nós, por causa da política dos Estados Unidos. Castro estava convencido - com razão - de que utilizaríamos todos os recursos necessários para derrotá-lo" (SMITH, 2013).
}

Desta forma, podemos destacar que o contexto e as opções de cada nação conduziram, igualmente, a dinâmica de conflito e, no caso cubano, a opção soviética que, embora dependente, indica uma relativa autonomia como observado na atuação cubana na América Latina e, principalmente, no apoio aos movimentos de libertação na África. Ainda, como aponta Ayerbe (2004), inúmeras medidas, de ambas as partes, contribuíram para o rompimento que se consolida em 1961 com a declaração do caráter socialista da revolução cubana4.

Desde então, a lógica do conflito determinou a relação com inúmeras medidas de parte a parte. No caso cubano, predominou a perspectiva (e necessidade, segundo seus dirigentes) de ampliação da revolução, o que levou ao engajamento cubano em diferentes continentes (Ásia, África e América Latina), ao desenvolvimento de uma perspectiva revolucionário, cujo grande adversário era os EUA, suas políticas ou governos simpáticos a estas. Do lado norte-americano, uma ocupação foi apoiada (a invasão da Bahia dos Porcos) e, posteriormente, se desenvolveu uma política de isolamento da experiência cubana fundamentada na doutrina de segurança nacional, na recepção de imigrantes cubanos (com mais benefícios que seus

\footnotetext{
${ }^{4} \mathrm{~A}$ bibliografia que desenvolve um balanço das relações entre Cuba e EUA é extensa, no entanto, para se perceber os principais aspectos além dos autores mencionados no texto, e com uma bibliografia contemporânea pode-se consultar: Alexander H. Delgado. "Las relaciones entre EUA y Cuba y la comunidade cubano-americana”, RevistaIberoamérica (ILARAN/Rússia), n. 4, 2015, pg. 100-122; Leandro Morgenfeld. “Estados Unidos-Cuba: un giro histórico que impacta América Latina y Caribe”, Revista Crítica y Emancipación (CLACSO), n. 12, julio-deciembre, 2014, pg. 103-146; a Revista de Estudios Estratégicos, CIPI (Cuba), n. 3, primer semestre de 2015.
} 
congêneres latino-americanos), na construção de um embargo comercial (de longa duração) e de inúmeras tentativas de desestabilizar o governo de Havana ou eliminar suas lideranças (Ayerbe, 2004; Dominguez, 2004). Tal política orientou as relações entre os anos 60 e 90.

Em suma, a lógica da Guerra Fria5 associada à construção da hegemonia estadunidense na região (Ayerbe, 2002) foi determinante para o padrão de conflito, e anormalidade, na relação entre ambas às nações. Neste sentido, como apontam Pecequilo e Forner:

\begin{abstract}
“O início da Guerra Fria, em 1947, representou o retorno das ações de intervenção e o congelamento da política regional. Á exceção da criação do Tratado Interamericano de Assistência Recíproca (TIAR) e da Organização dos Estados Americanos (OEA), respectivamente em 1947 e 1948, os EUA não apresentaram políticas específicas ao hemisfério. Na lógica da Doutrina Monroe, e da Guerra Fria, o hemisfério era 'fora dos limites' da disputa bipolar com a União Soviética e não haveria riscos ao sistema interamericano. Esta percepção ia se demonstrar equivocada e Cuba foi seu tipo ideal" (PECEQUILO e FORNER, 2015, pg. 28).
\end{abstract}

Com o fim da Guerra Fria e o desmantelamento do bloco soviético, emergiram perspectivas de que tal relação evoluísse para uma nova dinâmica que, no entanto, não se concretizou. Como aponta Dominguez, apesar da sensação inicial de vitória por parte do governo norte-americano no início da década, derivada da compreensão das dificuldades internas enfrentadas pelo regime e da diminuição da intensidade da projeção internacional de Cuba, com o fim da aliança com os soviéticos, o retorno das Forças Armadas Revolucionárias (FAR) ao país e a diminuição de seu apoio aos movimentos revolucionários, principalmente na América Latina, a estratégia fundamental dos EUA continuou sendo o acirramento do confronto, tornando tal questão um aspecto fundamental da política externa do país, através da promulgação de inúmeras leis e documentos que apontavam para o endurecimento do embargo econômico para castigar aliados e sócios comerciais do país (DOMINGUEZ, 2004, p. 274).

O resultado mais evidente deste processo foi o desenvolvimento de duas leis que procuravam aprofundar as dificuldades econômicas da ilha, partindo do pressuposto de que isto minaria o consenso e o apoio social ao regime, conduzindo necessariamente a um processo de transição que deporia Fidel Castro do poder. Em 1992, dentro do marco do Cuba Democracy Act, surgiu a lei Torriceli, proposta por um deputado do partido democrata, que reforçou o embargo proibindo as subsidiárias de empresas norte-americanas no exterior de comercializarem com Cuba, estabelecendo punições para comerciantes que negociassem e para países que fornecessem subsídios para a ilha e limitando o número de autorizações para turistas dos EUA viajarem a Cuba (AYERBE, 2004).

\footnotetext{
${ }^{5}$ Tal lógica é captada de forma abrangente pela noção de conflito intersistémico, desenvolvida por Halliday, que se refere ao período como "um conflito específico das relações interestatais, no qual as formas convencionais de rivalidade - militar, política, e econômica- são legitimadas por divergências de normas políticas e sociais." (pg.186). Além disto, vale destacar que tal conflito se estruturou a partir de três proposições: “(...) a- a rivalidade Leste-Oeste foi um produto do conflito entre dois sistemas sociais distintos; b- esta competição envolve uma dinâmica competitiva e universalizadora; e c- somente poderia ser concluída com um dos blocos prevalecendo sobre o outro. Desta forma, destaca-se que tal ordem teve um caráter específico no sistema internacional, não percebido pelas teorias convencionais, em que a disputa pelo poder passava pela obtenção de uma nova homogeneidade, isto é, o conflito só poderia terminar com o predomínio de um lado e, não por convergência ou compromisso. Enquanto existisse um dos lados a Guerra Fria não poderia terminar. E isto foi relativamente reconhecido pelos dois lados” (pg. 205). HALLIDAY, Fred. Repensando As Relações Internacionais. Porto Alegre: Editora da UFRGS, 1999.
} 
Já em 1996 o presidente Clinton aprofundou estas medidas sancionando a lei Helms-Burton. Tal lei contém quatro seções; a primeira regulamentava o embargo tornando-o lei e proíbe o presidente dos EUA de normalizar as relações com Cuba ou formular qualquer política sem a aprovação do congresso e, finalmente, estabelece que os diretores americanos de instituições financeiras internacionais não aceitem Cuba como membro e não concedam a aprovação de empréstimos para o país. A segunda seção enumerava os requisitos e fatores, combinação de restrições e incentivos, a serem empregados para avaliar se e quando é efetiva uma transição à democracia no país. Na terceira seção, concedia-se aos cidadãos e empresas norte-americanos o direito de processar, nos EUA, aqueles que utilizam propriedades nacionalizadas pelo governo cubano no início da revolução. E finalmente, a quarta seção impedia a entrada nos EUA de executivos de alto escalão e de acionistas majoritários, e suas famílias, das companhias que mantêm negócios com Cuba instalados nos imóveis que pertenciam a empresas americanas (AYERBE, 2004).

Como apontam Dominguez (2004) e Alzugaray Treto (2003), considerando o âmbito interno, tais ações reforçaram, ao invés de fragmentar, o apoio ao governo cubano propiciando a manutenção do discurso nacionalista, criaram um ambiente internacional mais favorável à recuperação econômica, pois diversos países se recusaram a agir conforme os interesses da diplomacia de Washington e continuaram suas relações econômicas com Cuba considerando a ilha um mercado aberto a seus interesses; e, finalmente, não contribuíram para o desenvolvimento da democracia (sob a égide norte-americana), ao propiciar ao regime cubano manter a unidade e diminuir o impacto de possíveis cisões, o qual afirmava enfrentar uma guerra com um inimigo poderoso e deveria, com isso, exercer maior controle interno (ALZUGARAY TRETO, 2003; DOMINGUEZ, 2004, SERBIN, 2011).

Em suma, a Guerra Fria continuou, até certo ponto, determinando a política interna e internacional do país. A face mais visível continua sendo a conflitiva relação com os EUA e o aprofundamento do embargo norte-americano. Somente a persistência da lógica da Guerra Fria, que se destaca entre outros elementos advindos da política interna do país como o lobby de parcela dos migrantes cubanos, parece explicar esse comportamento mesmo após a queda do bloco soviético, pois como afirma o último embaixador do país em Cuba:

“Os anos se passaram e ainda estamos na mesma situação absurda. Sempre me pergunto quais
são as razões que nos impedem de sentar à mesa de negociações e falar sobre nossas diferenças
para encontrar uma solução para esse conflito que já dura tanto. Conversamos com os chineses
e temos relações diplomáticas e comerciais perfeitamente normais com aquele país. Nós,
inclusive, normalizamos nossas relações com o Vietnã, contra quem travamos uma guerra
sangrenta, na qual perdemos mais de 50.000 soldados! Hoje o mundo é diferente" (SMITH, 2013).

Finalmente, a continuidade de tal lógica parece ser percebida, pelo menos por alguns setores de cada país, como equivocada e começa a ser superada com o anuncio da retomada das relações diplomáticas e a tentativa, em curso, de normalização de tal relação.

A recente reaproximação, com o reatamento dos laços diplomáticos, portanto só pode ser compreendida considerando os interesses que orientam a atuação dos grupos e setores que controlam a política de cada país, dirigidos por Raul Castro no caso cubano e por Barack Obama no estadunidense, e na perspectiva de construção, embora motivados por diferentes razões, de um novo arranjo regional. A isto 
podem ser agregados, como aponta López Segrera, dois fatores fundamentais: a percepção de que a ascensão de Raul Castro não afetaria a estabilidade do regime cubano e a crescente opinião, entre a classe política estadunidense e outros setores, da falência da estratégia tradicional (LÓPEZ SEGRERA, 2015)6.

No caso norte-americano, a administração de B. Obama procura enfatizar uma gestão de política interna e externa distinta e, com maior intensidade em seu segundo mandato, promove inovações no tratamento das questões globais e regionais, embora de forma branda, das perspectivas anteriores, procurando criar um legado para as futuras gerações. Neste sentido, tal gesto pode ser compreendido, como aponta Pecequilo e Forner (2015) como parte de um processo mais amplo, ancorada na proximidade do fim do mandato presidencial, de ações internas e externas que pudessem contribuir para um legado, pois:

\begin{abstract}
“a retomada das relações diplomáticas com Cuba no fim de 2014 faz parte do processo mais amplo de ofensivas políticas globais, regionais e internas do governo Obama (por isso a sua classificação intermestics). Em termos globais e regionais o processo detém duas dimensões: a do descongelamento das interações com nações ditas 'inimigas' (párias, rogué states no original), buscando cooptá-las para afastá-las de parcerias com outras potencias e enfraquecendo seu discurso de autonomia. A ação em Cuba muito se assemelha à negociação com o Irã para a interrupção de seu programa nuclear e permite um reposicionamento estratégico dos EUA. A segunda dimensão refere-se a incentivar ofensivas políticas positivas em questões controversas, colocando em xeque críticos das posições norte-americanas, esvaziando iniciativas de outras potências. (...) No que se refere à ofensiva doméstica, a questão cubana possui dimensões de contenção e cooptação de grupos de interesse, visando o fortalecimento do Partido Democrata, com foco nas eleições presidênciais de 2016” (PECEQUILO e FORNER, 2015, pg. 31-32).
\end{abstract}

Tal estratégica, para atrair o eleitorado hispânico e fortalecer a projeção regional e global do país, estabelecendo um legado também se fundamentou na constatação de que tal política não produzia os efeitos desejados, pois como mencionou Obama7, em sua histórica visita (março de 2016) a Cuba, ao discursar no grande Teatro de Havana, apontando que procurava superar uma herança da Guerra Fria: "Pero todavía muchas personas preguntan: ¿Por qué ahora? ¿Y por qué ahora? Y hay una simple respuesta: Lo que estaba haciendo Estados Unidos no funcionaba. Tenemos que tener la valentía de reconocer la verdad: una política de aislamiento diseñada para la guerra fría no tiene sentido en el siglo XXI, el embargo hería a los cubanos en vez de ayudarlos” (OBAMA, 2016).

Da mesma forma, consideramos fundamental a explicação multidimensional de Morgenfeld (2014) ao indicar que diversos fatores contribuíram para a ação estadunidense. Em primeiro lugar, inserem-se as motivações geopolíticas, pois Obama pretende recuperar a histórica posição hegemônica norte-americana na região e eliminar focos de resistências às políticas do país; no caso cubano, trata-se de aprofundar o processo de reinserção regional. Em seguida, estariam as motivações econômicas, pois enquanto os EUA pretendem acessar mercados e impulsionar sua atuação econômica regional, inclusive diante da ascensão da China ou de

\footnotetext{
${ }^{6}$ Apesar de polêmica e relativamente parcial, López Segrera (2015) defende a tese de que o fator fundamental para tal processo foi a gradual recuperação econômica cubana e, em menor medida, outros aspectos relacionados ao temor de uma crise migratória, a condenação (quase unânime) do bloqueio econômico, o constante rechaço de América Latina e União Européia (principais sócios comerciais da ilha) a política estadunidense, a presença econômica (cada vez maior) de China e Rússia na região, a tentativa dos EUA de recuperar sua imagem na região e, finalmente, a ação de setores empresariais que não querem ficar fora do (nascente) mercado insular.

${ }^{7}$ Antes de Obama, o governador de Nova York, ao visitar Cuba encabeçando uma missão comercial em abril de 2015, havia afirmado que: "Los 50 años de aislamiento no han funcionado. El compromisso y estabelecer relaciones es la mejor manera de tener un diálogo sobre las cosas en las que estamos de acuerdo y en las que no", citado DELGADO, Alexander H. "Las relaciones entre EUA y Cuba y la comunidade cubano-americana”, Revista Iberoamérica (ILARAN/Rússia), n. 4, 2015, pg. 113.
} 
líderes regionais como o Brasil, para Cuba trata-se de passar a ter acesso a mercado e capitais, bem como eliminar os efeitos nocivos do embargo econômico.

Além disto, como mencionado anteriormente, o ciclo eleitoral norte-americano contribuiu para tal iniciativa, como uma tentativa de obter o apoio hispânico, já almejado com a legislação migratória. Por fim, fatores de ordem geracional (de caráter pessoal e ideológico) parecem ter influenciado a tentativa de Obama, evidenciada em seus discursos, de superar uma política arraigada e sem efeitos, típica da Guerra Fria, impulsionando um aggiornamento da agenda norte-americana para o país e a região, enquanto que, para Raúl Castro, tal processo indica a possibilidade de conduzir e influenciar os rumos de tal aproximação, adotando um pragmatismo diferente de seu irmão, mas sem rupturas (MORGENFELD, 2014).

No caso cubano, a ascensão de Raúl Castro contribuiu para o desenvolvimento de um processo de atualização e reformas, denominado de "atualização do modelo", que, apesar de possuir uma grande complexidade e ter um caráter multidimensional pois atinge todos os aspectos da vida no país, se destaca por sua ênfase numa visão pragmática, interna e externamente, da política contemporânea que tem promovido mudanças na política doméstica e redefinições na política externa do país, com o desenvolvimento de novas estratégias e parcerias no cenário internacional (SERBIN, 2011).

Neste sentido, sob a liderança de Raúl tem se desenvolvido uma política mais pragmática, procurando solucionar problemas cotidianos da economia e política cubana, fundamentando-se em princípios e atitudes mais inclusivas e abrangentes que o discurso ideológico anterior (MESA-LAGO, 2012), embora sempre ressalte que a preservação das conquistas sociais da revolução (LÓPEZ SEGRERA, 2015) e da soberania nacional são elementos indiscutíveis em tal processo8. Diante disto, pode-se constatar que a combinação de interesses domésticos e internacionais, embora distintos dos estadunidenses, conduziram ao processo de reaproximação com os EUA.

Por fim, vale mencionar o papel de mediação desempenhado pela Igreja Católica. Tal mediação foi importante para o desenvolvimento dos contatos iniciais e deve ser compreendida a partir das novas idéias e posturas conduzidas pelo Papa Francisco I, como a tentativa de fortalecer uma agenda ambiental, a preocupação com os refugiados e os problemas relativos à desigualdade e à pobreza. Além disto, tal participação revela que a Igreja Católica tem se tornado a principal interlocutora do governo cubano, destacando-se na emergente sociedade civil do país e adquire relevância para atuar nos rumos do país.

\section{Cuba e EUA: o fim da Guerra Fria?}

Como aponta Delgado:

\footnotetext{
${ }^{8}$ Como afirmou Raul: “La actualización del modelo económico no es un milagro que pueda obrarse de la noche a la mañana, como algunos piensan; su despliegue total se logrará gradualmente en el transcurso del quinquenio, pues es mucho el trabajo de detalle, planificación y coordinación, tanto en el plano jurídico como en la preparación minuciosa de todos los que intervengan en su ejecución práctica. Estamos convencidos de que el principal enemigo que enfrentamos y enfrentaremos serán nuestras propias deficiencias y que por tanto, una tarea de tamaña dimensión para el futuro de la nación, no podrá admitir improvisaciones ni apresuramientos. No renunciaremos a hacer los cambios que hagan falta (...) los que efectuaremos al ritmo que demanden las circunstancias objetivas y siempre con el apoyo y comprensión de la ciudadanía, sin poner nunca en riesgo nuestra arma más poderosa, la unidad de la nación en torno a la Revolución y sus programas." Raúl Castro Ruz, Discurso en la clausura del VI Congreso del Partido Comunista de Cuba, GRANMA, 16 de abril de 2011.
} 
“La declaración conyunta de ambos mandatários, el 17 de diciembre del 2014, de restablecer relaciones diplomáticas tras un arduo y hermético proceso de negociaciones, donde el gobierno de Canadá y el Papa Francisco jugaron un rol fundamental constituye, sin lugar a dudas, una nueva fase, a pesar de la posibilidad de un mandato republicano en Washington para el próximo periodo presidencial" (DELGADO, 2015, p. 107).

Neste sentido, as medidas iniciais (liberação de viagens, envio de recursos, negociações comerciais pontuais, mudanças relativas a importação e exportação, dentre outras) de cada parte, para além da abertura de embaixadas, procuraram demonstrar um sinal de interesse na continuidade do processo mas, também, indicam as dificuldades de aprofundamento de tal processo, ao deixarem de lado aspectos relativos ao embargo, às indenizações de cada parte, ao sistema político e à base de Guantánamo, dentre outros.

Desta forma, pode-se compreender os impactos da recente (e histórica) visita de Obama a Cuba, pois, embora marcada pela cordialidade e pragmatismo, deixou evidente os desafios para a normalização das relações.

No caso cubano duas demandas parecem ser fundamentais, como menciona Delgado "el gobierno cubano ha reiterado que no puede haber relaciones normales 'mientras se mantega el bloqueo económico, comercial y financiero' que al igual que la base naval de Guantánamo son temas espinosos en el largo camino que se presenta" (DELGADO, 2015, p. 114). Além destas, certamente novas demandas (suspensão das transmissões da Rádio Martí em Miami ou as diversas facetas (como a indenização pelos efeitos do embargo) de cada aspecto podem dificultar o processo de normalização. Da parte estadunidense, pode-se apontar que as demandas relacionadas ao sistema político e económico, aos direitos humanos, a atuação da sociedade civil, bem como aspectos relativos às questões migratórias, dentre outras, podem também delimitar o aprofundamento de tal processo.

Um elemento importante a se considerar em relação a tal diminsão é que as demandas cubanas envolvem dimensões das relações bilaterais, não exigindo mudanças políticas internas e não estão relacionadas à ocupação de um território, enquanto algumas demandas norte-americanas parecem exigir mudanças na política interna cubana, o que, além de atingir a soberania do país, certamente irá dificultar o aprofundamento do processo.

Também neste sentido, o Ministro do Comércio Exterior e Inversão Estrangeira de Cuba, Rodrigo Malmierca Díaz, numa declaração à imprensa antes da chegada de Obama destacou que, apesar dos avanços, o obstáculo fundamental ainda é o embargo norte-americano, afirmando que:

\footnotetext{
"El bloqueo es el principal obstáculo al desarrollo de Cuba, como lo demuestran los perjuicios que ha provocado a nuestro país, que superan los 121 mil millones de dólares. Aun adoptando medidas como las que acabo de mencionar, que están al alcance de las facultades ejecutivas del presidente Obama, no podríamos alcanzar una real normalización de las relaciones, pues el bloqueo seguiría vigente y se mantendría pendiente la solución de otros temas de alta importancia para Cuba, como por ejemplo, la devolución del territorio ocupado por la base naval de Guantánamo" (DÍAZ, 2016).
}

A partir disto, pode-se considerar que tal visita foi histórica e relativamente exitosa, em certos aspectos; entretanto, a dinâmica das relações entre Cuba e EUA apresenta algumas potencialidades de cooperação e, principalmente, enfrentará inúmeros (e importantes) desafios, apresentados adiante. 
Em relação ao primeiro aspecto, a cooperação, concordamos com López Segrera (2015) ao afirmar que, apesar das incertezas dos cenários futuros, a reaproximação pode ser potencializada pelo desenvolvimento de cooperação em determinadas áreas, significando ganhos conjuntos, relacionadas à economia (turismo, investimentos, agricultura, petróleo, biotecnologia, dentre outras), defesa e segurança (acordos migratórios, segurança hemisférica e combate ao narcotráfico, para exemplificar), saúde pública (biotecnologia, produção de vacinas e ações humanitárias na região), ciência, cultura e esportes (em todas podem se desenvolver intercâmbio de profissionais e de programas), dentre outras. As ações cooperativas poderiam promover a confiança mútua, superando as décadas de desconhecimento, desconfiança e conflitos.

Em relação aos desafios, maiores e mais complexos, podemos destacar os seguintes elementos. Em primeiro lugar, as demandas cubanas (o embargo comercial, Guantánamo, a Rádio Martí, entre outras) e as demandas norte-americanas (relacionadas ao sistema político, direitos humanos e sociedade civil) podem dificultar o aprofundamento das medidas de aproximação, quando forem inseridas na mesa de negociação.

Além disto, existem incertezas sobre o significado de tal reaproximação para as políticas norteamericanas para a região. Ou seja, deve-se observar se esta representará (ou não) uma alteração da posição da América Latina na política externa norte-americana e a superação dos padrões tradicionais de hegemonia e dominação desenvolvidos ao longo do século XX. Desta forma, se tal aproximação significar somente a tentativa de reposição da hegemonia norte-americana para Cuba e a América Latina e repetição do padrão histórico é difícil imaginar sua consolidação e aprofundamento. Se, pelo contrário, significar o desenvolvimento de um novo patamar nas relações regionais, sua possibilidade de sucesso será maior.

Finalmente, podemos destacar que a evolução de tal reaproximação dependerá, em grande medida, da dinâmica política interna de cada país. Neste caso, concordamos com Juan Valdés Paz quando afirmar que:

\footnotetext{
"Más en general, las próximas etapas del proceso de normalización se enfrentarán del lado norteamericano a las modalidades que futuras administraciones darán a su política hacia Cuba y al peso que le darán en ella a sus premisas geopolíticas . Del lado cubano influirá la marcha de su recuperación económica, los cambios institucionales y el grado de penetración que los Estados Unidos hayan alcanzado para entonces en la economía y la sociedad cubana" (Valdés Paz, 2016).
}

Em suma, apesar das expectativas e avanços iniciais as relações entre Cuba e EUA ainda enfrentarão uma longa e ardorosa negociação, considerando as demandas apontadas, para que se estabeleça uma efetiva normalização. Neste sentido, coincidimos com Morgenfeld ao apontar que: “(...) Esto muestra que las negociaciones entre los gobiernos de Washington y La Habana serán más largas y complejas que lo que muchos pronosticaron en diciembre pasado" (MORGENFELD, 2014, p. 135). Portanto, trata-se do primeiro passo de uma longa, e necessária, jornada de superação definitiva das heranças da Guerra Fria na América Latina e da tentativa de construção de relações equilibradas no continente.

\section{Conclusão}

As relações entre Cuba e EUA sempre foram marcadas pela anormalidade ou pelo arranjo desafiador do equilíbrio entre autonomia e dependência, entre proximidade e conflito. O processo, em curso, embora apresente inúmeras possibilidades e cenários prospectivos, pode-se constituir numa nova oportunidade para 
que, finalmente, tal relação possa se orientar por uma dinâmica de normalidade, como orienta o sistema internacional.

Este trabalho procurou discutir o processo, complexo e tortuoso, da retomada das relações entre Cuba e EUA e sua normalização efetiva, algo inédito na relação entre estes países e importante para a superação das heranças da Guerra Fria na América Latina. Para tanto, buscou compreender as motivações, a dinânica, os desafios e os impactos de tal processo de reaproximação nas relações regionais e sua perspectiva entre Cuba e EUA.

Desta forma, este trabalho demonstrou que uma convergência de interesses foi determinante para o início das negociações e o papel mediador desempenhado pela Igreja Católica, que tem se destacado como principal interlocutora do regime cubano, e pelo governo canadense foi fundamental para tal reaproximação. Ainda, tal processo, apesar das iniciativas já desenvolvidas de parte a parte depende, em grande medida, da forma como serão consideradas e solucionadas as demandas que se acumularam ao longo de anos de conflito e são requisito fundamental para seu aprofundamento e uma efetiva normalização.

Por fim, apontou que tal continuidade depende além do encaminhamento adequado de tais demandas, dos interesses estratégicos envolvidos e da consolidação de uma nova postura norte-americana para as questões regionais. Além disto, a dinámica política interna, em Cuba relacionada à transição e nos EUA derivada do resultado do pleito presidencial e da ascensão de Trump, serão determinantes para a superação (ou não) dos desafios.

Em suma, a retomada das relações representou o primeiro, e importante passo, num processo que tende a ser complexo, lento e tortuoso, mas fundamental para que a América Latina e os EUA possam instaurar uma nova dinâmica nas relações regionais, contribuindo para o desenvolvimento e a justiça social.

\section{BIBLIOGRAFIA}

AYERBE, L. F. A Revolução Cubana. São Paulo: Editora UNESP, 2004.

AYERBE, L. F. Estados Unidos e a América Latina: a construção da hegemonia. São Paulo: Editora UNESP, 2002.

ALZUGARAY TRETO, C. "La política exterior de Cuba en la década de 90: intereses, objetivos y resultados". Política Internacional, La Habana, vol. I, n. 1, p. 14-32, enero-julio 2003.

BANDEIRA, Luiz Alberto Moniz. De Martí a Fidel: A Revolução Cubana e a América Latina. Rio de Janeiro: Civilização Brasileira, 1998.

COGGIOLA, Osvaldo. Revolução cubana: história e problemas atuais. São Paulo, Ed. Xamã, 1998.

DELGADO, Alexander H. “Las relaciones entre EUA y Cuba y la comunidade cubano-americana”. In: Revista Iberoamérica, ILARAN (Rússia), n. 4, 2015, pg. 100-122.

DÍAZ, Rodrigo Malmierca. "Declaración ante la prensa de Rodrigo Malmierca Díaz, Ministro del Comercio Exterior y la Inversión Extranjera de Cuba”. In: Jornal GRANMA, 19/03/2016. Disponible em http://www.granma.cu (acesso em 20/08/2016) 
DOMÍNGUEZ, J. I. La política exterior de Cuba y el sistema internacional. In: TULCHIN, Joseph; ESPACH, Ralph. América Latina en el nuevo sistema internacional. Barcelona: Bellaterra, 2004, pp. 255-286.

HALLIDAY, Fred. Repensando as Relações Internacionais. Porto Alegre: Editora da UFRGS, 1999.

LÓPEZ SEGRERA, Francisco. Cuba-EEUU: de enemigos cercanos a amigos distantes (1959-2015). Barcelona: El Viejo Topo, 2015, 172 pgs.

LÓPEZ SEGRERA, Francisco. "La Revolución Cubana y los desafios de la Política Social”. In: Contrapuntos, El País, 19 de septiembre de 2015. Disponível em: http://blogs.elpais.com/contrapuntos/2015/09/larevolucion-cubana-y-los-desafios-de-la-politica-social.html (acesso em 10/11/2015).

MESA-LAGO, C. Cuba en la era de Raúl Castro - reformas económico-sociales y sus efectos. Madri: Ed. Colibri, 2012.

MORGENFELD, Leandro. "Estados Unidos-Cuba: un giro histórico que impacta América Latina y Caribe”. In: Revista Crítica y Emancipación (CLACSO), n. 12, julio-deciembre, 2014, pg. 103-146.

OBAMA, Barack. Discurso no Grande Teatro Nacional. La Habana: Jornal GRANMA, 23/03/2016. Disponível em http://www.granma.cu (acesso em 25/03/2016).

PECEQUILO E FORNER, Cristina S. e Clarissa Nascimento. Os EUA e Cuba: uma agenda intermestics. Boletim Meridiano 47, vol. 16, n. 147, janeiro-fevereiro, 2015, p. 27-33.

RUZ, Raúl Castro. “Discurso en la clausura del VI Congreso del Partido Comunista de Cuba”. In: GRANMA, 16 de abril de 2011 (acesso em 10/11/2015).

SERBIN, A. 2011. "Círculos concéntricos: la política exterior de Cuba en un mundo multipolar y el proceso de “actualización”. In: AYERBE, L. F. (Org.). Cuba, Estados Unidos y América Latina frente a los desafios hemisféricos. Barcelona; Buenos Aires: Içaria; Cries.

SMITH, W. "EUA sempre rechaçam diálogo cubano, diz último embaixador norte-americano em Havana" (Entrevista). In: Ópera Mundi, jornal eletrônico, 20 e 21/07/2013, (acessado em 02/08/2015).

VALDÉS PAZ, Juan. “Cuba-EUA. Los desafios de la normalización”. Revista Temas, 06/04/2016, La Habana. Disponível em: http://temas.cult.cu (acesso em 15/08/2016). 


\title{
RESUMO
}

O presente trabalho discute o restabelecimento das relações diplomáticas entre Cuba e EUA, oficializado em 2014, procurando analisar sua dinâmica e os desafios para uma normalização efetiva. Para tanto, discute as motivações, de parte a parte, que conduziram a este processo e determinaram a retomada dos laços diplomáticos, rompidos desde princípios dos anos 60, substituindo, ainda que parcialmente, a política conflituosa que havia imperado em tal relação. Em seguida, analisa as percepções e as principais ações desde o anúncio de tal retomada e discute as demandas apresentadas por cada parte para uma efetiva normalização. Neste sentido, apresenta as demandas cubanas (fim do embargo econômico, reparações de recursos, relações abertas e transparentes, fim de programas destinados a destituir governo do país, entre outras) e as demandas estadunidenses (reformas políticas e econômicas, sociedade civil e direitos humanos, indenizações, formas de propriedade, entre outras), procurando demonstrar que há um longo caminho a percorrer até a normalização efetiva de tal relação. Tal caminho será determinado tanto pela solução a tais demandas como pela dinâmica da política interna de cada país que pode conduzir, ou não, a superação da lógica do conflito que havia predominado.

Palavras-clave: Cuba, EUA, Guerra-Fria, Normalização;

\begin{abstract}
The present paper discusses the reestablishment of diplomatic relations between Cuba and the USA, made official in 2014, seeking to analyze its dynamics and the challenges that hinder its effective normalization. In order to do so, it discusses the motivations that led to this process and determined the resumption of diplomatic ties, which had been broken since the beginning of the 1960s, replacing, albeit partially, the conflicting politics that had prevailed in this relationship. It then analyzes the perceptions and main actions since the announcement of such resumption and discusses the demands presented by each party for an effective normalization. In this sense, it presents the Cuban demands (end of the economic embargo, reparations of resources, open and transparent relations, end of programs destined to deprive government of the country, among others) and the American demands (political and economic reforms, civil society and human rights, Indemnities, forms of property, among others), trying to demonstrate that there is a long way to go until the effective normalization of such relationship. Such a path will be determined both by the solution to such demands and by the dynamics of the domestic politics of each country that may or may not lead to overcoming the logic of the conflict that had prevailed.
\end{abstract}

Key-words: Cuba, USA, Cold War, Normalization; 